\title{
The role of soluble fiber intake in patients under highly effective lipid-lowering therapy
}

Silvia C Ramos ${ }^{1}$, Francisco A Fonseca' ${ }^{1}$, Soraia H Kasmas' ${ }^{1}$ Flávio T Moreira', Tatiana Helfenstein ${ }^{1}$, Ney C Borges², Ronilson A Moreno ${ }^{2}$, Vinicius M Rezende ${ }^{2}$ Fernanda C Silva ${ }^{2}$ and Maria C Izar $^{1 *}$

\begin{abstract}
Background: It has been demonstrated that statins can increase intestinal sterol absorption. Augments in phytosterolemia seems related to cardiovascular disease.

Objective: We examined the role of soluble fiber intake in endogenous cholesterol synthesis and in sterol absorption among subjects under highly effective lipid-lowering therapy.

Design: In an open label, randomized, parallel-design study with blinded endpoints, subjects with primary hypercholesterolemia ( $n=116$ ) were assigned to receive during 12 weeks, a daily dose of $25 \mathrm{~g}$ of fiber (corresponding to $6 \mathrm{~g}$ of soluble fibers) plus rosuvastatin $40 \mathrm{mg}(n=28)$, rosuvastatin $40 \mathrm{mg}$ alone $(n=30)$, sinvastatin $40 \mathrm{mg}$ plus ezetimibe $10 \mathrm{mg}$ plus $25 \mathrm{~g}$ of fiber $(\mathrm{n}=28)$, or sinvastatin $40 \mathrm{mg}$ plus ezetimibe $10 \mathrm{mg}$ ( $\mathrm{n}$ = 30) alone.
\end{abstract}

Results: The four assigned therapies produced similar changes in total cholesterol, LDL-cholesterol, and triglycerides ( $p<0.001$ vs. baseline) and did not change HDL-cholesterol. Fiber intake decreased plasma campesterol ( $p<0.001$ vs. baseline), particularly among those patients receiving ezetimibe ( $p<0.05$ vs. other groups), and $\beta$-sitosterol ( $p=0.03$ vs. baseline), with a trend for lower levels in the group receiving fiber plus ezetimibe $(p=0.07)$. Treatment with rosuvastatin alone or combined with soluble fiber was associated with decreased levels of desmosterol ( $p=0.003$ vs. other groups). Compared to non-fiber supplemented individuals, those treated with fibers had weight loss $(p=0.04)$, reduced body mass index $(p=0.002)$ and blood glucose $(p=$ 0.047).

Conclusion: Among subjects treated with highly effective lipid-lowering therapy, the intake of $25 \mathrm{~g}$ of fibers added favorable effects, mainly by reducing phytosterolemia. Additional benefits include improvement in blood glucose and anthropometric parameters.

Keywords: Soluble fiber, lipids, campesterol, desmosterol, lipid-lowering therapy

\section{Introduction}

Dietary fiber is widely prescribed [1], alone or associated with lipid-lowering therapies, in order to reduce cholesterol levels [2]. The exact mechanism by which soluble fibers lower serum LDL-cholesterol levels is not completely understood. However, there are evidences suggesting that soluble fibers may interfere with lipid and/or bile acid metabolism [3].

\footnotetext{
* Correspondence: mcoizar@terra.com.br

'Department of Medicine, Cardiology Division, Federal University of Sao

Paulo, Rua Pedro de Toledo, 276, São Paulo, SP, 04039-030, Brazil

Full list of author information is available at the end of the article
}

Atherosclerosis has been recognized as a complex disease related in part to lipid disorders. Beyond cholesterol content of lipoproteins, a moderate increase in phytosterolemia seems related to cardiovascular disease $[4,5]$.

Based on clinical trials, high doses of statins have been recommended to achieve lower levels of LDL-cholesterol [6-8]. Nevertheless, the use of high doses of statins is not always well tolerated or effective and the concomitant use of ezetimibe has been proposed. Due to the blockade of the endogenous cholesterol synthesis [9], statins appear related to increased intestinal absorption of sterols, both cholesterol and plant sterols $[10,11]$.
C Biomed Central

(c) 2011 Ramos et al; licensee BioMed Central Ltd. This is an Open Access article distributed under the terms of the Creative Commons Attribution License (http://creativecommons.org/licenses/by/2.0), which permits unrestricted use, distribution, and reproduction in any medium, provided the original work is properly cited. 
Ezetimibe has an important synergism with statins in reducing $\mathrm{LDL}$-cholesterol and is able to prevent the increase in intestinal sterols absorption [12,13]. On the other hand, the inhibition of cholesterol absorption increases the endogenous cholesterol synthesis [14-16].

The Framingham Offspring Study showed that cholesterol synthesis markers were associated with reduction in cardiovascular disease risk and, in contrast, absorption markers were associated with an almost two-fold increased risk [17].

Although changes in lifestyle, including a prudent diet [1] have been widely recommended for primary or secondary prevention of cardiovascular disease, the usefulness of a soluble fiber-enriched diet, in patients under highly effective lipid-lowering therapy is less reported, not only for the achievement of lipid goals, but particularly to the balance between phytosterolemia and cholesterol synthesis.

Therefore, we hypothesized that soluble fiber intake can reduce plant sterols absorption among subjects receiving highly effective lipid-lowering therapy. The role of fiber intake was tested in two different lipid-lowering strategies, using high-dose statin or the combination of a statin plus a cholesterol absorption inhibitor. These drugs and dosages were chosen to attain similar changes in lipid profile through distinct mechanisms.

\section{Subjects and methods}

\section{Design and study population}

We performed a prospective, randomized, open label study, with parallel arms and blinded endpoints. Patients were recruited from the outpatient unit of dyslipidemias of our university. The trial protocol was conducted in accordance with the ethical standards of the institution on human experimentation and approval was obtained from the local ethics committee. Informed consent was obtained from all participants prior inclusion. Eligible patients were men and women, 30 to 75 years of age, in primary or secondary prevention of coronary heart disease, who had an indication for lipid-lowering therapy in accordance with the National Cholesterol Education Program/Adult Treatment Panel (NCEP/ATP III) guidelines [1]. A total of 116 subjects completed the study protocol. Patients with liver, renal or gastrointestinal disease, malignancies, uncontrolled metabolic disorder, that might affect the tolerability or safety of the treatments were excluded. Exclusion criteria during the study were low adherence (less than $80 \%$ ) to either the lipid-lowering regimen or to the daily fiber intake. The major characteristics of the study population are listed in the Table 1. Risk factors and metabolic syndrome were defined by the NCEP/ATP III guidelines [1].

The 24-hour dietary recall [18] was obtained at the beginning and end of the study. Before treatment, all patients received nutritional counseling based on the Therapeutic Lifestyle Changes of the NCEP/ATP III [1]. Then, they were randomized to receive or not $44 \mathrm{~g}$ of the passion fruit peel flour, to ensure a minimum daily consumption of $6 \mathrm{~g}$ of soluble fiber and to achieve the target of $25 \mathrm{~g}$ of fiber intake, divided into three daily doses administered before meals. They were also randomized to rosuvastatin $40 \mathrm{mg}$ or the combination of simvastatin $40 \mathrm{mg}$ plus ezetimibe $10 \mathrm{mg}$, daily for 12 weeks. The lipid-lowering agents and the fiber were given to the patients every 30 days, with reinforcement of lifestyle changes and to evaluate the adherence to the study protocol.

\section{Study drugs and fiber}

Rosuvastatin (Crestor ${ }^{\circledR}$, IPR Pharmaceuticals, Porto Rico), Simvastatin/Ezetimibe (Zetsim ${ }^{\circledR}$, Schering-Plough Products, Las Piedras, Porto Rico) were gifts from AstraZeneca and Merck Co, respectively. The passion fruit peel flour was purchased from Tango alimentos (Londrina, PR, Brazil). The composition of passion fruit peel flour was analyzed by Centro de Ciências e Qualidade de Alimentos (Instituto de Tecnologia de Alimentos, Campinas, SP, Brazil), which revealed that $44 \mathrm{~g}$ of flour corresponded to $45 \mathrm{kcal}$ of total energy, being $25 \mathrm{~g}$ of total fiber, $6 \mathrm{~g}$ of soluble fiber, $5 \mathrm{mg}$ of campesterol, and $35 \mathrm{mg}$ of $\beta$-sitosterol.

\section{Blood sample collection and assays Lipids and biochemistry}

Biochemical analyses were performed in samples obtained after a 12-hour fasting period at baseline and after 12 weeks of treatment in a central laboratory of our university using automated techniques (Advia 2400, Siemens Healthcare Diagnostics, Tokyo, Japan). Serum cholesterol, HDL-cholesterol, and triglycerides were determined by automated methods (Advia 2400, Siemens Healthcare Diagnostics, Tokyo, Japan). LDL-cholesterol was calculated using the Friedewald formula [19]. Glycated hemoglobin was assayed by high-performance liquid chromatopraphy (Tosho G2, Tosho Inc., Tokyo, Japan), apolipoprotein A1, apolipoprotein B, and highly-sensitive $\mathrm{C}$-reactive protein were determined by nephelometry (Array $360 \mathrm{CE} / \mathrm{AL}$, Beckmann Coulter, Inc. Brea, CA).

\section{Phytosterols and desmosterol}

For the quantification of beta-sitosterol and campesterol (markers of sterols absorption), as well as for desmosterol (precursor of the endogenous cholesterol synthesis) we used ultra performance liquid chromatography (UPLC) and mass spectrometry (MS). Briefly, these sterols were quantitated in plasma samples by a method developed and run by Synchrophar, Campinas, SP, Brazil. The sterols were detected as its free forms, i.e., non-esterified, 
Table 1 Baseline characteristics of the study population by group

\begin{tabular}{|c|c|c|c|c|c|}
\hline & $\begin{array}{c}\text { RSV+Fib } \\
N=28\end{array}$ & $\begin{array}{c}\text { RSV } \\
N=30\end{array}$ & $\begin{array}{c}\text { SIM/EZE+Fib } \\
N=28\end{array}$ & $\begin{array}{c}\text { SIM+EZE } \\
\mathrm{n}=30\end{array}$ & P-value \\
\hline Age, years $^{1}$ & $57(1)$ & $60(2)$ & $62(1)$ & $58(1)$ & 0.21 \\
\hline Female, $\mathrm{n}(\%)^{2}$ & $21(75)$ & $20(67)$ & $19(68)$ & $22(73)$ & 0.87 \\
\hline Hypertension, $\mathrm{n}(\%)^{2}$ & $22(79)$ & $24(80)$ & $18(64)$ & $26(87)$ & 0.22 \\
\hline Diabetes, $\mathrm{n}(\%)^{2}$ & $5(18)$ & $7(23)$ & $6(21)$ & $9(30)$ & 0.73 \\
\hline Smoking, $\mathrm{n}(\%)^{2}$ & $2(7)$ & $3(10)$ & $1(4)$ & $2(7)$ & 0.82 \\
\hline Metabolic Syndrome, n (\%) ${ }^{2}$ & $17(61)$ & $18(60)$ & $13(46)$ & $14(47)$ & 0.53 \\
\hline
\end{tabular}

Differences between groups were analyzed by ANOVA ${ }^{1}$, or Pearson's chi-square test ${ }^{2}$. RSV = rosuvastatin; Fib = fiber; SIM = simvastatin; EZE = ezetimibe.

monitoring the ions with $\mathrm{m} / \mathrm{z}, 367.30$ for desmosterol, 397.25 for $\beta$-sitosterol and 383.60 for campesterol. The levels of compounds were determined by comparison of peak response against a calibration curve from $0.5 \mu \mathrm{g} / \mathrm{mL}$ to $10.0 \mu \mathrm{g} / \mathrm{mL}$. Samples presenting higher levels than $10.0 \mu \mathrm{g} / \mathrm{mL}$ were diluted to compare with calibration levels. Results were transformed to $\mathrm{mg} / \mathrm{dL}$.

\section{Statistical analyses}

Results are expressed as mean (SEM) or percentages unless otherwise specified. Continuous variables were tested for distribution of normality by KolmogorovSmirnov test. Comparisons between groups at baseline were made by ANOVA or Pearson's Chi square test. For comparisons between timepoints and groups we used General Linear Model (GLM) - repeated measures or Kruskal-Wallis test, when data were presented as percentages. To compare non-fiber supplemented and fiber-supplemented groups, the 2-sided Student's independent or paired t-test or Mann-Whitney test were used. When appropriate, continuous variables were log transformed. Statistical significance was set at a p-value $<0.05$. All analyses were made using the SPSS 17.0 for windows (SPSS Inc, Chicago, IL).

\section{Results}

\section{Dietary intake, weight and body mass index}

The analyses of the dietary recall have shown that the consumption of cholesterol and dietary fiber did not differ between groups; monounsaturated, polyunsaturated, or trans-fatty acids were also similar. Energy intake was reduced at the 12 weeks ( $\mathrm{p}=0.001$ vs. baseline, GLMrepeated measures), with energy from carbohydrates, fatty acids, and proteins being comparable among groups. The estimated daily fiber intakes, obtained from dietary recall were not different along the study, when fiber supplementation with passion fruit peel flour was not counted (Table 2).

Regarding the soluble fiber status, those with the addition of fiber presented weight ( $\mathrm{p}=0.04$, Student's $\mathrm{t}$-test) and BMI reduction $(\mathrm{p}=0.002$, Student's t-test) on week 12 (Figure 1A-B).

\section{Laboratory results}

\section{Lipids and apolipoproteins}

In Table 3 we present our main laboratory findings. Twelve-week treatment with lipid-lowering agents with or without fiber supplementation was associated with effective reduction of total cholesterol ( $\mathrm{p}<0.0001 \mathrm{vs}$. baseline, GLM-repeated measures), LDL-cholesterol ( $\mathrm{p}<0.001$ vs. baseline, GLM-repeated measures) and triglycerides ( $<<$ 0.001 vs. baseline, GLM-repeated measures), without changes in HDL-cholesterol levels. Apolipoprotein B serum levels were lower after a 12-week treatment period ( $\mathrm{p}<0.001$ vs. baseline, GLM-repeated measures), whereas we observed higher levels of Apolipoprotein A1 ( $p=0.035$ vs. baseline, GLM-repeated measures), without differences between treatments. Differences on lipids and apolipoproteins according to fiber intake status were not significant (data not shown).

\section{Desmosterol and phytosterols}

Desmosterol plasma levels presented interaction between groups. Subjects receiving rosuvastatin have shown decreased levels of desmosterol in comparison with the subjects treated with simvastatin plus ezetimibe ( $p=0.003$ vs. other groups)

Sterol intestine absorption markers, campesterol and $\beta$-sitosterol, are presented in Table 3. There was a decrease in campesterol plasma levels at the end of treatment ( $\mathrm{p}<0.001$ vs. baseline, GLM-repeated measures), with lower levels observed in subjects receiving fibers and treated with simvastatin plus ezetimibe $(\mathrm{p}=0.005$ between groups, GLM-repeated measures). Campesterol levels were lower for those subjects taking soluble fibers on week 12 ( $\mathrm{p}=0.025$ vs. non-fiber supplemented, Student's independent $\mathrm{t}$-test) as shown in Figure 1C. There was a decrease in plasma levels of $\beta$-sitosterol $(p=0.03$ vs. baseline) with a trend for lower levels in the group receiving fibers plus ezetimibe $(p=0.07)$. Fiber intake status did not affect $\beta$-sitosterol plasma levels.

\section{Glucose, glycated hemoglobin and C-reactive protein}

Blood glucose and glycated hemoglobin (HbA1c) did not change along the study between groups (Table 3). However, there were differences in glucose percent change in subjects supplemented with fibers when compared with 
Table 2 Characteristics of the diet consumed at baseline and 12 weeks, by group

\begin{tabular}{|c|c|c|c|c|c|}
\hline & RSV+Fib & RSV & $\begin{array}{c}\text { SIM/EZE } \\
+ \text { Fib }\end{array}$ & $\begin{array}{c}\mathrm{SIM}_{\text {+EZE }} \\
\text { S }\end{array}$ & $\begin{array}{c}\mathrm{P}- \\
\text { value }\end{array}$ \\
\hline & $N=28$ & $\mathrm{~N}=30$ & $\mathrm{~N}=28$ & $\mathrm{n}=30$ & \\
\hline \multicolumn{6}{|l|}{ MUFA\% ${ }^{1}$} \\
\hline Baseline & $13.8(0.7)$ & $12.8(0.7)$ & $13.4(1.0)$ & $11.8(0.7)$ & 0.374 \\
\hline 12 weeks & $12.9(0.6)$ & $13.6(0.8)$ & $13.4(0.5)$ & $11.5(0.6)$ & 0.094 \\
\hline \multicolumn{6}{|l|}{ PUFA\% ${ }^{1}$} \\
\hline Baseline & $9.1(0.6)$ & $11.9(1.0)$ & $10.3(0.8)$ & $10.3(1.0)$ & 0.329 \\
\hline 12 weeks & $8.3(0.8)$ & $10.7(1.1)$ & $9.6(0.6)$ & $8.2(0.7)$ & 0.098 \\
\hline \multicolumn{6}{|l|}{ SAFA $\%^{1}$} \\
\hline Baseline & $9.7(0.6)$ & $9.5(0.6)$ & $9.5(0.5)$ & $9.1(0.6)$ & 0.833 \\
\hline 12 weeks & $9.3(0.5)$ & $9.4(0.5)$ & $9.5(0.7)$ & $8.9(0.7)$ & 0.717 \\
\hline \multicolumn{6}{|l|}{ Trans FA\% ${ }^{1}$} \\
\hline Baseline & $0.3(0.1)$ & $0.4(0.1)$ & $0.3(0.1)$ & $0.3(0.1)$ & 0.608 \\
\hline 12 weeks & $0.3(0.1)$ & $0.4(0.1)$ & $0.4(0.2)$ & $0.4(0.1)$ & 0.237 \\
\hline \multicolumn{6}{|c|}{ Energy Kcal/day ${ }^{2}$} \\
\hline Baseline & $\begin{array}{l}1762 \\
(116)\end{array}$ & $\begin{array}{l}1766 \\
(100)\end{array}$ & $1828(156)$ & $\begin{array}{l}1741 \\
(136)\end{array}$ & $0.001^{\mathrm{a}}$ \\
\hline 12 weeks & $\begin{array}{l}1653 \\
(116)\end{array}$ & $\begin{array}{l}1520 \\
(85)\end{array}$ & 1585 (129) & $\begin{array}{l}1599 \\
(102)\end{array}$ & $0.990^{b}$ \\
\hline \multicolumn{6}{|l|}{ Lipids$\%^{1}$} \\
\hline Baseline & $36.1(1.4)$ & $37.3(1.9)$ & $36.3(1.7)$ & $34.3(1.8)$ & 0.941 \\
\hline 12 weeks & $33.9(1.4)$ & $36.9(1.8)$ & $35.7(1.2)$ & $31.4(1.6)$ & 0.041 \\
\hline \multicolumn{6}{|c|}{ Carbohydrates $\%{ }^{1}$} \\
\hline Baseline & $46.4(1.9)$ & $46.9(2.1)$ & $46.7(2.3)$ & $49.2(2.1)$ & 0.869 \\
\hline 12 weeks & $46.3(1.5)$ & $46.5(1.6)$ & $46.7(1.7)$ & $52.1(1.8)$ & 0.034 \\
\hline \multicolumn{6}{|l|}{ Proteins $\%{ }^{1}$} \\
\hline Baseline & $18(1.3)$ & $16.5(1.0)$ & $17.7(1.3)$ & $17.3(0.9)$ & 0.79 \\
\hline 12 weeks & $20(1.0)$ & $17.6(0.9)$ & $18.5(1.2)$ & $17.8(0.8)$ & 0.268 \\
\hline \multicolumn{6}{|l|}{$\begin{array}{l}\text { Cholesterol mg/ } \\
\text { day }^{2}\end{array}$} \\
\hline Baseline & $214(29)$ & $200(21)$ & $197(33)$ & $210(29)$ & $0.203^{a}$ \\
\hline 12 weeks & $222(29)$ & $157(12)$ & $201(34)$ & $171(22)$ & $0.683^{b}$ \\
\hline \multicolumn{6}{|l|}{ Fibers g/day ${ }^{2}$} \\
\hline Baseline & $20(3)$ & $17(1)$ & $22(3)$ & $16(2)$ & $0.853^{\mathrm{a}}$ \\
\hline 12 weeks & $20(2)$ & $16(1)$ & $18(2)$ & $19(2)$ & $0.666^{a}$ \\
\hline
\end{tabular}

Differences analyzed by Kruskal-Wallis test ${ }^{1}$ or General Linear Model-repeated measures followed by Tukey's test ${ }^{2}$, with $p$-values for comparisons ${ }^{a}$ between visits and between groups.

MUFA $=$ monounsaturated fatty acids; PUFA $=$ polyunsaturated fatty acids SAFA = saturated fatty acids; RSV = rosuvastatin $40 \mathrm{mg} ;$ Fib = fiber; SIM = simvastatin $40 \mathrm{mg}$; EZE = ezetimibe $10 \mathrm{mg} ; \mathrm{FA}=$ fatty acids.

those not receiving fibers [mean (SEM) - 2.9 (1.8) \% vs. $0.6(4.3) \%, p=0.038$, Mann-Whitney test]. Glucose levels were lower in subjects supplemented with fibers on week 12 ( $\mathrm{p}=0.035$ vs. non-supplemented, Student's independent t-test); data shown in Figure 1D.

Highly-sensitive C-reactive protein serum levels were elevated at baseline and decreased similarly between treatment groups ( $\mathrm{p}<0.001$ vs. baseline, GLM-repeated measures) (Table 3). We did not observe differences in highly-sensitive $\mathrm{C}$-reactive protein according to fiber intake status (data not shown).

\section{Discussion}

This study examined the role of fiber supplementation in patients under effective therapy with lipid-lowering drugs. It has been reported that consumption of soluble fibers promotes a moderate effect in lowering cholesterol in hypercholesterolemic patients [20,21]. However, the literature is scarce in relation to the benefit of fibers added to therapy in patients taking effective lipid-lowering agents. Our study has shown that no further reduction was achieved in total cholesterol, LDL-cholesterol, and triglycerides when fibers were added to an effective therapy. However, fibers seemed to act synergistically with ezetimibe, reducing phytosterolemia, at the recommended dose for total $(25 \mathrm{~g})$ and soluble fibers $(6 \mathrm{~g})$ intake [1].

However, the addition of fibers to the diet, even in patients receiving highly effective therapy can bring important benefits [22,23]. It has been reported that use of statins alone may increase the absorption of sterols by the intestine, causing mild to moderate increase in plasma phytosterols [14]. This increase appears to be related to statin dose $[15,16,24]$. Although phytosterolemia, as recessive genetic disease related to deficiency of ABCG5/G8 carriers, is very rare, mild to moderate increases in phytosterolemia may be associated with increased cardiovascular risk $[4,25]$, although this topic is still controversial [26]. The greatest contribution of our study was to show that the use of fibers in patients on highly effective lipid-lowering therapy, in order to reduce LDL-C $>50 \%$ and attain guideline goals, can prevent the increase in plant sterols plasma levels. Furthermore, among patients receiving therapy with simvastatin and ezetimibe, the use of fibers produced significant decrease in phytosterolemia. These findings seem of importance, because they support evidence for supplementation of fibers being a safe strategy when added to the most effective lipid-lowering strategies, reducing the absorption of phytosterols. These aspects seem yet more relevant for subjects bearing common polymorphisms of the NPC1L1 or ABCG5/G8 genes. Genetic variation in these genes were reported and can increase the absorption of sterols or decrease sterol extrusion to the intestinal lumen, which are associated with increased levels of phytosterolemia [27].

Other benefits of fiber supplementation observed in our patients were weight loss and the achievement of lower body mass index. The reduction in total energy intake may have contributed to these results, however, differences between groups were only observed in patients receiving fiber supplementation. Our findings are in agreement with previous studies showing inverse relationship between fiber intake and weight loss $[28,29]$.

Another interesting finding of the study was the mild reduction in blood glucose in subjects receiving fiber 

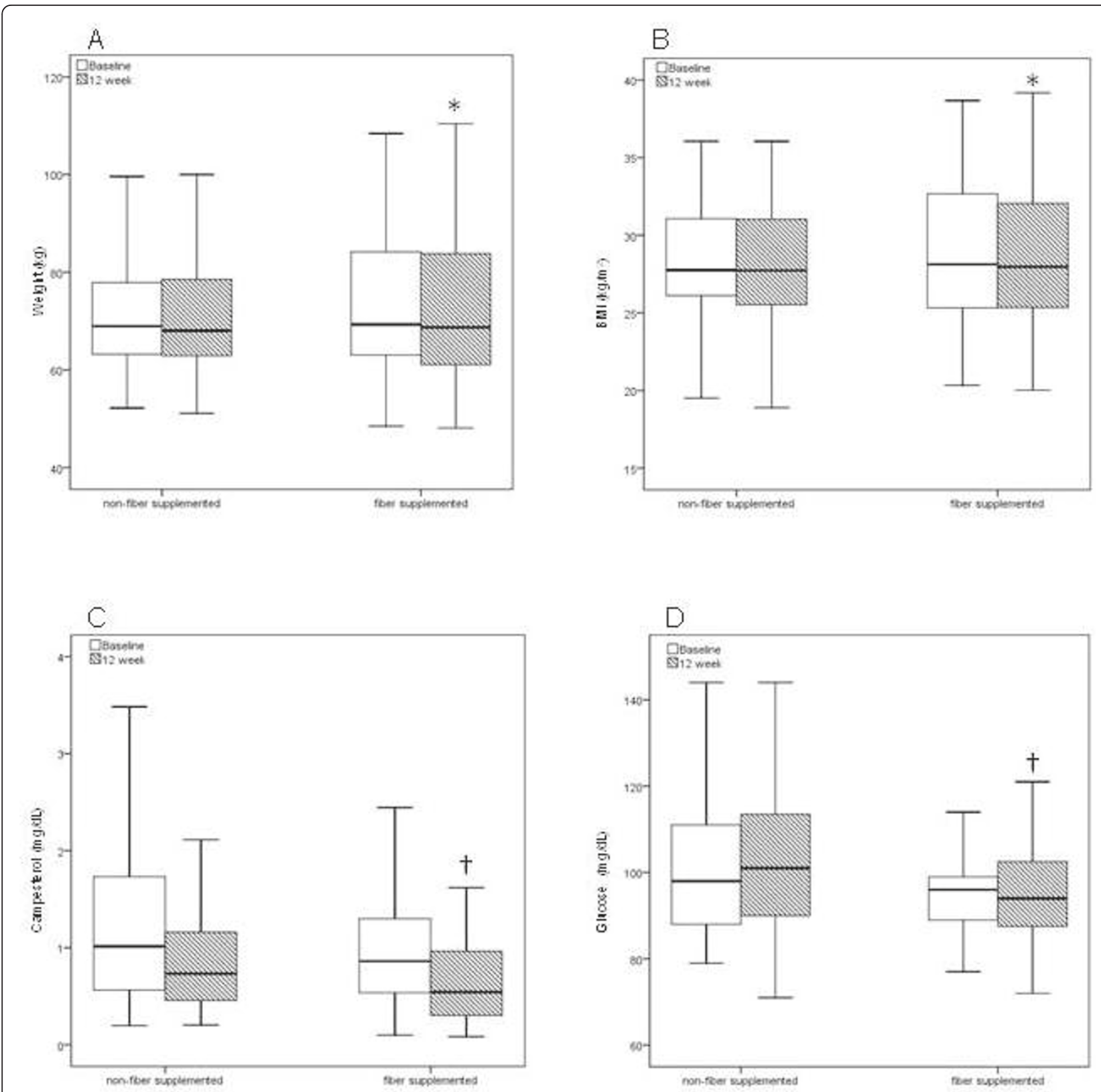

Figure 1 Box plots of (A) Weight, (B) BMI, (C) Campesterol and (D) Glucose at baseline (white bars) and 12 weeks (dashed bars). Fibersupplemented subjects presented mild reduction in body weight ( ${ }^{*} p=0.04$ vs. non-fiber supplemented, Student's paired t-test), body mass index ( ${ }^{*} p=0.002$ vs. non-fiber supplemented, Student's paired t-test), reduction in campesterol levels $\left({ }^{*} p=0.033\right.$ vs. non-fiber supplemented, Student's paired t-test; $\uparrow p=0.025$ vs. non-fiber supplemented, Student's independent t-test) and in blood glucose ( $† p=0.035$ vs. non-fiber supplemented, Student's independent t-test). BMI = body mass index.

supplementation. Previous studies have demonstrated reduction in fasting glucose, postprandial and glycated hemoglobin levels associated with soluble fiber intake [30-33]. Recently, two meta-analyses have shown a slight increase in the rates of new-onset diabetes mellitus in patients treated with statins $[34,35]$. Another contribution of fiber intake is the potential benefit for reduction in new cases of diabetes, attributed to statin therapy.

\section{Study strenghts and limitations}

According to a recent meta-analysis of statin trials [36], lipid-lowering therapy that promotes greater reductions in LDL-cholesterol produces definite further reductions in the incidence of cardiovascular events. Therefore, our study tested the benefit of fiber intake in this scenario.

It is possible that the lipid effects of soluble fiber have been masked by the highly effective treatment used in 
Table 3 Anthropometric and laboratory parameters at baseline and 12 weeks, by group

\begin{tabular}{|c|c|c|c|c|c|c|}
\hline & $\begin{array}{c}\text { RSV+Fib } \\
N=28\end{array}$ & $\begin{array}{c}\text { RSV } \\
N=30\end{array}$ & $\begin{array}{c}\text { SIM/EZE+Fib } \\
N=\mathbf{2 8}\end{array}$ & $\begin{array}{c}\text { SIM+EZE } \\
n=30\end{array}$ & P-value $^{1}$ & P-value $^{2}$ \\
\hline \multicolumn{7}{|l|}{ Weight kg } \\
\hline Baseline & $74(3)$ & $72(2)$ & $73(3)$ & $70(2)$ & 0.001 & 0.803 \\
\hline 12 weeks & $73(3)$ & $72(3)$ & $72(3)$ & $70(2)$ & & \\
\hline \multicolumn{7}{|l|}{$\mathrm{BMl} \mathrm{kg/ \textrm {m } ^ { 2 }}$} \\
\hline Baseline & $28(1)$ & $30(1)$ & $30(1)$ & $28(1)$ & 0.005 & 0.246 \\
\hline 12 weeks & $27(1)$ & $30(1)$ & $29(1)$ & $28(1)$ & & \\
\hline \multicolumn{7}{|l|}{ Glucose mg/dL } \\
\hline Baseline & $97(2)$ & $104(4)$ & $103(5)$ & $108(7)$ & 0.754 & 0.257 \\
\hline 12 weeks & $95(2)$ & $104(4)$ & $100(4)$ & $109(6)$ & & \\
\hline \multicolumn{7}{|l|}{$\mathrm{HbA1c} \%$} \\
\hline Baseline & $5.7(0.1)$ & $6.3(0.2)$ & $6.0(0.2)$ & $6.2(0.2)$ & 0.02 & 0.215 \\
\hline 12 weeks & $5.8(0.1)$ & $6.2(0.2)$ & $6.1(0.2)$ & $6.3(0.2)$ & & \\
\hline \multicolumn{7}{|l|}{ hsCRP mg/L } \\
\hline Baseline & $4.2(1.1)$ & $3.7(0.5)$ & $3.3(0.4)$ & $4.5(1.3)$ & $<0.001$ & 0.976 \\
\hline 12 weeks & $2.4(0.5)$ & $2.5(0.4)$ & $2.3(0.4)$ & $2.3(0.4)$ & & \\
\hline \multicolumn{7}{|c|}{ Cholesterol mg/dL } \\
\hline Baseline & $256(10)$ & $244(8)$ & $247(8)$ & $241(9)$ & $<0.0001$ & 0.639 \\
\hline 12 weeks & $149(6)$ & $140(5)$ & $155(9)$ & $147(8)$ & & \\
\hline \multicolumn{7}{|l|}{ LDL-C mg/dL } \\
\hline Baseline & $167(8)$ & $154(7)$ & $162(6)$ & $158(8)$ & $<0.001$ & 0.436 \\
\hline 12 weeks & $70(5)$ & $64(4)$ & $80(8)$ & $72(4)$ & & \\
\hline \multicolumn{7}{|l|}{$\mathrm{HDL}-\mathrm{C} \mathrm{mg} / \mathrm{dL}$} \\
\hline Baseline & $57(3)$ & $52(2)$ & $52(2)$ & $54(2)$ & 0.392 & 0.351 \\
\hline 12 weeks & $57(3)$ & $50(3)$ & $53(3)$ & $52(2)$ & & \\
\hline \multicolumn{7}{|c|}{ Triglycerides mg/dL } \\
\hline Baseline & $160(13)$ & $187(16)$ & $158(14)$ & $144(10)$ & $<0.001$ & 0.291 \\
\hline 12 weeks & $110(9)$ & $123(8)$ & $110(7)$ & $108(9)$ & & \\
\hline \multicolumn{7}{|c|}{ Apoliprotein A1 mg/dL } \\
\hline Baseline & $153(6)$ & $145(6)$ & $141(4)$ & $147(3)$ & 0.035 & 0.482 \\
\hline 12 weeks & $155(6)$ & $149(6)$ & $145(5)$ & $152(4)$ & & \\
\hline \multicolumn{7}{|c|}{ Apoliprotein B mg/dL } \\
\hline Baseline & $133(6)$ & $133(5)$ & $133(5)$ & $134(6)$ & $<0.001$ & 0.775 \\
\hline 12 weeks & $68(3)$ & $67(3)$ & $73(5)$ & $70(4)$ & & \\
\hline \multicolumn{7}{|c|}{ Campesterol mg/dL } \\
\hline Baseline & $1.2(0.2)$ & $1.1(0.1)$ & $0.9(0.1)$ & $1.3(0.2)$ & $<0.001$ & 0.005 \\
\hline 12 weeks & $0.9(0.1)$ & $1.0(0.1)$ & $0.5(0.1)$ & $0.8(0.1)$ & & \\
\hline \multicolumn{7}{|c|}{$\beta$-sitosterol mg/dL } \\
\hline Baseline & $0.7(0.1)$ & $0.8(0.1)$ & $0.6(0.1)$ & $0.9(0.1)$ & 0.03 & 0.072 \\
\hline 12 weeks & $0.6(0.6)$ & $0.7(0.1)$ & $0.5(0.1)$ & $0.6(0.1)$ & & \\
\hline \multicolumn{7}{|c|}{ Desmosterol mg/dL } \\
\hline Baseline & $0.7(0.1)$ & $1.9(1.6)$ & $0.9(0.3)$ & $0.5(0.1)$ & 0.005 & 0.373 \\
\hline 12 weeks & $0.6(0.1)$ & $0.9(0.5)$ & $1.0(0.3)$ & $1.6(0.5)$ & & \\
\hline
\end{tabular}

Differences analyzed by General Linear Model-repeated measures, followed by Tukey's test. HbA1c = glycated hemoglobin; hs-CRP = highly-sensitive C-reactive protein; RSV = rosuvastatin $40 \mathrm{mg}$; Fib = fiber; SIM = simvastatin $40 \mathrm{mg}$; EZE = ezetimibe $10 \mathrm{mg}$. 'Differences between baseline and 12 week; ${ }^{2}$ Differences between groups. 
our study. Furthermore, fiber effects on anthropometric parameters could be more pronounced in subjects with obesity and/or diabetes, and when fiber is consumed at longer periods.

\section{Conclusions}

Soluble fiber intake in patients receiving effective strategies with lipid-lowering drugs seems important for the achievement of lower phytosterolemia (synergistic action with ezetimibe), and is associated with weight loss, and lower levels of plasma glucose.

SCR carried out the clinical protocol, performed statistical analysis and drafted the manuscript. FAF conceived of the study, participated in its design and coordination, performed statistical analysis and drafted the manuscript. SHK carried out the assessment of plasma sterols. FTM carried out the clinical protocol. TH performed statistical analysis; NCB and RAM standardized the assay of plasma sterols. VMR and FCS carried out the assays of plasma sterols. MCI conceived of the study, participated in its design and coordination, performed statistical analysis and drafted the manuscript.

All authors read and approved the final manuscript.

\section{Acknowledgements}

$\mathrm{MCl}$ has received research grant from FAPESP (Foundation for Research of the State of Sao Paulo, Brazil). SCR has received research grant from CNPq (National Council for Research and Development, Brazil).

\section{Author details}

'Department of Medicine, Cardiology Division, Federal University of Sao Paulo, Rua Pedro de Toledo, 276, São Paulo, SP, 04039-030, Brazil. ${ }^{2}$ Synchrophar, Praça Vinte e Oito de Fevereiro, 55, Paulínia, 13140-000, SP, Brazil.

\section{Competing interests}

The authors declare that they have no competing interests.

Received: 8 January 2011 Accepted: 2 August 2011

Published: 2 August 2011

\section{References}

1. National Cholesterol Education Program (NCEP) Expert Panel on Detection, Evaluation, and Treatment of High Blood Cholesterol in Adults (Adult Treatment Panel III) final report. Circulation 2002, 106(25):3143-421.

2. Ortega RM, Palencia A, Lopez-Sobaler AM: Improvement of cholesterol levels and reduction of cardiovascular risk via the consumption of phytosterols. Br J Nutr 2006, 96(Suppl 1):S89-93.

3. Theuwissen E, Mensink RP: Water-soluble dietary fibers and cardiovascular disease. Physiol Behav 2008, 94(2):285-92.

4. Assmann G, Cullen P, Erbey J, Ramey DR, Kannenberg F, Schulte H: Plasma sitosterol elevations are associated with an increased incidence of coronary events in men: results of a nested case-control analysis of the Prospective Cardiovascular Munster (PROCAM) study. Nutr Metab Cardiovasc Dis 2006, 16(1):13-21.

5. Patel MD, Thompson PD: Phytosterols and vascular disease. Atherosclerosis 2006, 186(1):12-9.

6. Ma Y, Griffith JA, Chasan-Taber L, Olendzki BC, Jackson E, Stanek EJ, Li W, Pagoto SL, Hafner AR, Ockene IS: Association between dietary fiber and serum C-reactive protein. Am J Clin Nutr 2006, 83(4):760-6.
7. Asztalos BF, Le Maulf F, Dallal GE, Stein E, Jones PH, Horvath KV McTaggart F, Schaefer EJ: Comparison of the effects of high doses of rosuvastatin versus atorvastatin on the subpopulations of high-density lipoproteins. Am J Cardiol 2007, 99(5):681-5.

8. van Himbergen TM, Matthan NR, Resteghini NA, Otokozawa S, Ai M, Stein EA, Jones PH, Schaefer EJ: Comparison of the effects of maximal dose atorvastatin and rosuvastatin therapy on cholesterol synthesis and absorption markers. J Lipid Res 2009, 50(4):730-9.

9. Catapano AL, Davidson MH, Ballantyne CM, Brady WE, Gazzara RA, Tomassini JE, Tershakovec AM: Lipid-altering efficacy of the ezetimibe/ simvastatin single tablet versus rosuvastatin in hypercholesterolemic patients. Curr Med Res Opin 2006, 22(10):2041-53.

10. Grodos D, Tonglet R: Scandinavian simvastatin study (4S). Lancet 1994, 344(8939-8940):1768.

11. Miettinen TA, Gylling $H$, Lindbohm N, Miettinen TE, Rajaratnam RA, Relas $H$ : Serum noncholesterol sterols during inhibition of cholesterol synthesis by statins. J Lab Clin Med 2003, 141(2):131-7.

12. Plat J, Bragt MC, Mensink RP: Common sequence variations in ABCG8 are related to plant sterol metabolism in healthy volunteers. J Lipid Res 2005, 46(1):68-75.

13. Davis HR, Veltri EP: Zetia: inhibition of Niemann-Pick C1 Like 1 (NPC1L1) to reduce intestinal cholesterol absorption and treat hyperlipidemia. J Atheroscler Thromb 2007, 14(3):99-108.

14. Miettinen TA, Gylling $H$, Lindbohm N, Miettinen TE, Rajaratnam RA, Relas $H$, Finnish Treat-to-Target Study Investigators: Serum noncholesterol sterols during inhibition of cholesterol synthesis by statins. J Lab Clin Med 2003, 141(2):131-7.

15. Miettinen TA, Gylling $\mathrm{H}$ : Cholesterol synthesis and absorption in coronary patients with lipid triad and isolated high LDL cholesterol in a $4 \mathrm{~S}$ subgroup. Atherosclerosis 2003, 168(2):343-9.

16. Assmann G, Kannenberg F, Ramey DR, Musliner TA, Gutkin SW, Veltri EP Effects of ezetimibe, simvastatin, atorvastatin, and ezetimibe-statin therapies on non-cholesterol sterols in patients with primary hypercholesterolemia. Curr Med Res Opin 2008, 24(1):249-59.

17. Matthan NR, Pencina M, LaRocque JM, Jacques PF, D'Agostino RB, Schaefer EJ, Lichtenstein AH: Alterations in cholesterol absorption/ synthesis markers characterize Framingham offspring study participants with CHD. J Lipid Res 2009, 50(9):927-35.

18. Bingham SA, Gill C, Welch A, Day K, Cassidy A, Khaw KT, Sneyd MJ, Key TJ, Roe L, Day NE: Comparison of dietary assessment methods in nutritional epidemiology: weighed records $v$. $24 \mathrm{~h}$ recalls, food-frequency questionnaires and estimated-diet records. Br J Nutr 1994, 72(4):619-43.

19. Friedewald WT, Levy RI, Fredrickson DS: Estimation of the concentration of low-density lipoprotein cholesterol in plasma, without use of the preparative ultracentrifuge. Clin Chem 1972, 18(6):499-502.

20. Marlett JA, McBurney MI, Slavin JL: Position of the American Dietetic Association: health implications of dietary fiber. J Am Diet Assoc 2002, 102(7):993-1000.

21. Brown L, Rosner B, Willett WW, Sacks FM: Cholesterol-lowering effects of dietary fiber: a meta-analysis. Am J Clin Nutr 1999, 69(1):30-42.

22. Anderson JW, Baird P, Davis RH Jr, Ferreri S, Knudtson M, Koraym A, Waters V, Williams CL: Health benefits of dietary fiber. Nutr Rev 2009, 67(4):188-205.

23. Anderson JW: Dietary fiber, lipids and atherosclerosis. Am J Cardiol 1987, 60(12):17G-22G

24. Gylling H, Puska P, Vartiainen E, Miettinen TA: Serum sterols during stanol ester feeding in a mildly hypercholesterolemic population. J Lipid Res 1999, 40(4):593-600.

25. Ketomaki A, Gylling H, Miettinen TA: Effects of plant stanol and sterol esters on serum phytosterols in a family with familial hypercholesterolemia including a homozygous subject. J Lab Clin Med 2004, 143(4):255-62.

26. Miettinen TA, Gylling $H$ : The effects of statins and sitosterols: benefit or not? Curr Atheroscler Rep 2009, 11(1):23-7.

27. Davis HR Jr, Altmann SW: Niemann-Pick C1 Like 1 (NPC1L1) an intestinal sterol transporter. Biochim Biophys Acta 2009, 1791(7):679-83.

28. Salas-Salvado J, Farres X, Luque X, Narejos S, Borrell M, Basora J, Anguera A, Torres F, Bulló M, Balanza R, Fiber in Obesity-Study Group: Effect of two doses of a mixture of soluble fibres on body weight and metabolic variables in overweight or obese patients: a randomised trial. $\mathrm{Br} J$ Nutr 2008, 99(6):1380-7. 
29. Tucker LA, Thomas KS: Increasing total fiber intake reduces risk of weight and fat gains in women. J Nutr 2009, 139(3):576-81.

30. Vuksan V, Rogovik AL, Jovanovski E, Jenkins AL: Fiber facts: benefits and recommendations for individuals with type 2 diabetes. Curr Diab Rep 2009, 9(5):405-11.

31. Panahi S, Ezatagha A, Temelli F, Vasanthan T, Vuksan V: Beta-glucan from two sources of oat concentrates affect postprandial glycemia in relation to the level of viscosity. J Am Coll Nutr 2007, 26(6):639-44.

32. Mello VD, Laaksonen DE: Dietary fibers: current trends and health benefits in the metabolic syndrome and type 2 diabetes. Ara Bras Endocrinol Metabol 2009, 53(5):509-18.

33. Kim H, Stote KS, Behall KM, Spears K, Vinyard B, Conway JM: Glucose and insulin responses to whole grain breakfasts varying in soluble fiber, beta-glucan: a dose response study in obese women with increased risk for insulin resistance. Eur J Nutr 2009, 48(3):170-5.

34. Rajpathak SN, Kumbhani DJ, Crandall J, Barzilai N, Alderman M, Ridker PM Statin therapy and risk of developing type 2 diabetes: a meta-analysis. Diabetes Care 2009, 32(10):1924-9.

35. Sattar N, Preiss D, Murray HM, Paul Welsh, Brendan MBuckley, Anton JMde Craen, Sreenivasa Rao Kondapally Seshasai, John JMcMurray, Dilys JFreeman, Wouter JJukema, Peter WMacfarlane, Chris JPackard, David JStott, Rudi GWestendorp, James Shepherd, Barry RDavis, Sara LPressel, Roberto Marchioli, Rosa Maria Marfisi, Aldo PMaggioni, Luigi Tavazzi, Gianni Tognoni, John Kjekshus, et al: Statins and risk of incident diabetes: a collaborative meta-analysis of randomised statin trials. Lancet 2010, 375(9716):735-42.

36. Cholesterol Treatment Trialists' (CTT) Collaboration, Baigent C, Blackwell L Emberson J, Holland LE, Reith C, Bhala N, Peto R, Barnes EH, Keech A, Simes J, Collins R: Efficacy and safety of more intensive lowering of LDL cholesterol: a meta-analysis of data from 170,000 participants in 26 randomised trials. Lancet 2010, 376(9753):1670-81.

doi:10.1186/1475-2891-10-80

Cite this article as: Ramos et al: The role of soluble fiber intake in patients under highly effective lipid-lowering therapy. Nutrition Journal $201110: 80$

\section{Submit your next manuscript to BioMed Central and take full advantage of:}

- Convenient online submission

- Thorough peer review

- No space constraints or color figure charges

- Immediate publication on acceptance

- Inclusion in PubMed, CAS, Scopus and Google Scholar

- Research which is freely available for redistribution

Submit your manuscript at www.biomedcentral.com/submit 